\title{
Infección invasiva por Listeria monocytogenes en un paciente con síndrome de Evans.
}

\section{Invasive Listeria monocytogenes infection in a patient with Evan's syndrome.}

Pág. 39,45

Recibido: 09-05-2020

Aceptado: 12-06-2020

Dr. Erick Méndez Ramírez ${ }^{1}$

Dra. Jeinny Maroto Fernández ${ }^{2}$

1. Médico Especialista en Medicina Interna. Hospital de San Carlos. Caja Costarricense del Seguro Social. Costa Rica.

2. Médico Especialista en Medicina Interna. Hospital de San Carlos. Caja Costarricense del Seguro Social. Costa Rica.

\section{RESUMEN.}

Listeria monocytogenes es una bacteria intracelular facultativa que tiene predilección por causar infecciones del sistema nervioso central en humanos. Cuya población de riesgo predominante es lactantes, adultos mayores y en estados de inmunosupresión. Los principales síndromes clínicos causados por Listeria monocytogenes incluyen gastroenteritis febril, infección perinatal e infecciones sistémicas marcadas por infecciones del sistema nervioso central con o sin bacteriemia. Presentamos el caso de un paciente masculino de 66 años portador de síndrome de Evans en tratamiento inmunosupresor quien acude al servicio de emergencias del Hospital San Carlos el 27 de agosto de 2019, por un cuadro agudo de fiebre, cefalea y ataque al estado general en quien se documenta síndrome de respuesta inflamatoria sistémica y meningitis bacteriana ante lo cual inicio empíricamente cefotaxime. El panel molecular y los hemocultivos fueron positivos por Listeria monocytogenes. El paciente recibió 3 semanas de antibioticoterapia con ampicilina con excelente evolución clínica y sin secuelas neurológicas.

\section{PALABRAS CLAVE.}

Listeria monocitogenes, meningitis, síndrome de Evans.

\section{ABSTRACT}

Listeria monocytogenes is a facultative intracellular bacterium that has a predilection for causing central nervous system infections in 
humans. Whose predominant risk population is infants, the elderly and in immunosuppressed states. The main clinical syndromes caused by Listeria monocytogenes include febrile gastroenteritis, perinatal infection, and systemic infections marked by central nervous system infections with or without bacteremia. We present the case of a 66-year-old male patient with Evans syndrome undergoing immunosuppressive treatment who went to the emergency service of the San Carlos Hospital on August 27, 2019, for an acute picture of fever, headache, and attack on the general condition in whom Systemic inflammatory response syndrome and bacterial meningitis are documented, leading to cefotaxime empirically. The molecular panel and blood cultures were positive for Listeria monocytogenes. The patient received 3 weeks of antibiotic therapy with ampicillin with excellent clinical evolution and without neurological sequelae.

\section{KEY WORDS.}

Listeria monocitogenes, meningitis, Evan's Syndrome.

\section{PRESENTACIÓN DEL CASO.}

Masculino de 66 años, conocido hipertenso, diabético tipo II, con diagnóstico de síndrome de Evans hace 4 años, en tratamiento crónico con insulina NPH 20-00-20 unidades subcutáneas, insulina simple 4-4-4 unidades subcutáneas, enalapril $20 \mathrm{mg}$ día, hidroclorotiazida $25 \mathrm{mg}$ día, azatioprina $300 \mathrm{mg}$ día, micofenolato de mofetilo 3 gramos día, prednisolona $75 \mathrm{mg}$ día, y en ese momento en espera de aprobar rituximab.

Dentro de sus antecedentes quirúrgicos destaca esplenectomía en dos ocasiones (bazo accesorio). Ingresó por cuadro agudo de un día de evolución de sensación febril no cuantificada, ataque al estado general y nauseas. En la exploración física afebril taquicárdico, normotenso, pálido, con fascies de dolor, consciente, cardiopulmonar estable, sin afección de funciones mentales superiores, no focalización neurológica, no alteración de pares craneales.

En los laboratorios iniciales se documenta bicitopenia (hemoglobina $9,7 \mathrm{mg} / \mathrm{dl}$, plaquetas $70,000)$ sin leucocitosis, hiperbilirrubinemia leve de predominio indirecto y reactantes de fase aguda elevados (PCR 18,8mg/dl, presepsina $560 \mathrm{pg} / \mathrm{ml}$ ). En ese momento se decide tomar cultivos de sangre, orina e iniciar cobertura antibiótica empírica con cefotaxime $2 \mathrm{~g} \mathrm{IV}$ cada 8 horas antes posible proceso infeccioso de foco no claro e ingresar al salón de medicina interna.

Una vez ingresado en medicina interna paciente aqueja cefalea global, de intensidad 9 de 10, que empeora con los movimientos e irradia a región cervical, acompañado de nauseas; se realiza punción lumbar.

El análisis del liquido cefalorraquídeo con leucocitos $30 / \mathrm{mm}^{3}$ ( $80 \%$ neutrófilos), glucosa $63 \mathrm{mg} / \mathrm{dl}$, proteínas $251 \mathrm{mg} / \mathrm{dl}$, GRAM negativo, tinta china negativa, VDRL no reactivo. Concomitantemente se reporta hemocultivos positivos a las 20 horas por bacilos gran positivos, por lo cual se suspende cefotaxime y se inicia ampicilina $2 \mathrm{~g}$ iv cada 4 horas. 12 horas posterior a reporte de hemocultivo se aísla en panel molecular de sepsis L. monocytogenes.

El paciente recibió 3 semanas de tratamiento con ampicilina intravenosa teniendo una excelente evolución y resolución de síntomas ante lo cual se egresó sin ninguna secuela neurológica. 


\section{DISCUSIÓN}

El síndrome de Evans es una enfermedad autoinmune poco común que fue definida por Robert Evans en 1951 cuando estudió la relación entre la anemia hemolítica autoinmune (AlHA) y la púrpura trombocitopénica inmune (PTI). Describió los primeros criterios de diagnóstico de ES, incluida la presencia de anemia, reticulocitosis, aumento de la bilirrubina en sangre y urobilinógeno fecal, sin antecedentes familiares de enfermedades hemolíticas, evidencia de anticuerpos contra eritrocitos a $37^{\circ} \mathrm{C}$, hemólisis de eritrocitos transfundidos, presencia de púrpura. , tiempo de sangrado prolongado, aspiración de médula ósea con un número normal o aumentado de megacariocitos y la ausencia de agentes tóxicos exógenos o una enfermedad basal. El curso típico del síndrome de Evans se caracteriza por una enfermedad crónica heterogénea con variabilidad clínica al inicio, remisiones espontáneas y exacerbaciones. Su frecuencia mundial es desconocida(1).

No hay ensayos clínicos disponibles para el tratamiento del síndrome de Evans y las indicaciones para comenzar la terapia no se han establecido mediante estudios basados en evidencia. Pocos informes retrospectivos y pequeñas cohortes tienen respuestas documentadas. El objetivo principal consiste en lograr una respuesta completa a largo plazo. No existe un régimen terapéutico establecido. Los esteroides con y sin inmunoglobulinas se recomiendan como terapia de primera línea. La transfusión de glóbulos rojos / plaquetas está indicada solo en pacientes sintomáticos graves debido al riesgo de exacerbaciones(2).

El rango de opciones para la terapia de segunda línea incluye agentes inmunosupresores [ciclosporina, micofenolato mofetilo (MMF) y danazol], rituximab y quimioterapia (vincristina).
La esplenectomía también puede considerarse un tratamiento de segunda línea. La mayoría de los datos son anecdóticos y no concluyentes, con una interpretación difícil debido al uso concomitante de corticosteroides y otras modalidades.

Durante la revisión de la literatura mundial no se encuentran publicaciones que documenten la asociación de síndrome de Evans y listeria, siendo nuestro caso posiblemente el primer caso reportado hasta ahora. Hay algunas asociaciones con otras enfermedades sistémicas del tejido conectivo como lo es con lupus eritematoso sistémico, documentando un riesgo relativo de 18,3; la forma más frecuente es la bacteremia(3).

Listeria monocytogenes es el agente etiológico responsable de la listeriosis, es un bacilo grampositivo, anaerobio facultativo y capaz de crecer en el citoplasma celular, y se encuentra ampliamente distribuido en la naturaleza y en la cadena alimentaria. La vía más común de infección son los alimentos contaminados, a diferencia de otros patógenos, se multiplica por alimentos refrigerados con temperaturas de $4^{\circ}$ a $10^{\circ} \mathrm{C}(4)$. La infección suele presentarse como casos aislados y, eventualmente, como brotes epidémicos.

Estudios anteriores han encontrado que la mayoría de los pacientes ( $>60 \%$ ) con meningitis por Listeria son inmunocomprometidos 0 ancianos. Se informaron muchas afecciones incluidas la terapia inmunosupresora, malignidad, enfermedad del tejido conectivo, diabetes mellitus, alcoholismo, asplenia, cirrosis hepática, enfermedad renal en etapa terminal e infección por VIH. En este caso el sindrome de Evans juega un papel importante como factor de riesgo. Sin embargo, esos factores, además de la

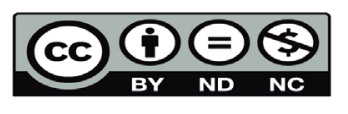


vejez, se han reconocido durante mucho tiempo como riesgos importantes que predisponen a la meningitis neumocócica (5).

Un estudio prospectivo observacional en pacientes italianos mayores de 50 años en un solo centro comparó 22 casos de meningitis por listeria y 109 casos de meningitis neumocócica. El grupo encontró una asociación entre Listeria y la terapia inmunosupresora actual (6).

La incidencia de listeriosis en el mundo es de 3 a 6 casos por millón de habitantes por año(7). La listeriosis generalmente presenta baja incidencia, pero su mortalidad oscila entre un $20-30 \%$, denotando una gran carga de la enfermedad (5).

Está bien establecido que muchos serotipos diferentes de L. monocytogenes generalmente se aíslan de los alimentos, mientras que un subconjunto limitado de serotipos (es decir, 1 / $2 a, 1 / 2 b$ y $4 b$ ) son responsables de una gran parte de los casos clínicos en todo el mundo.

\section{FISIOPATOLOGÍA}

La conversión del saprofito ambiental a un microorganismo patógeno entraña una regulación coordinada de los factores bacterianos que determinan la patogenia y que median el acceso al interior de las células, el crecimiento intracelular y la diseminación intercelular (8).

La Listeria monocytogenes induce su propia interiorización por las células que normalmente no son fagocíticas, esta entrada a las células es mediada por las proteínas de superficie del hospedador clasificadas como internalinas. Un factor esencial que determina la patogenia de L. monocytogenes es su hemolisina $\beta$, llamada listeriolisina $O$. La listeriolisina $O$, es una citolisina formadora de poros y dependientes del colesterol, la cual se caracteriza por ser el principal mediador de la rotura de la membrana fagosómicaqueseformadespuésdelafagocitosis de L. monocytogenes. Además, la listeriolisina O, actúa como poro de traslocación para una o las dos fosfolipasas de L. monocytogenes que al igual que la listeriolisina $\mathrm{O}$, contribuyen a la lisis de las vacuolas. Las mutaciónes en esta citolisina, que influyen en su síntesis, semivida o $\mathrm{pH}$ óptimo, producen toxicidad prematura en las células infectadas.

Poco después de la exposición al citosol de la célula de mamífero, la bacteria produce otra proteína de superficie. ActA, que media la nucleación de los filamentos de actina del hospedador para impulsar las bacterias hacia el interior de las células y entre las mismas, esto permite un mecanismo patógeno relacionado que logra la diseminación intercelular sin la exposición al medio extracelular.

Las listerias que sobreviven a la actividad bactericida de los macrófagos infectados en un inicio proliferan en el citosol, y se diseminan de una célula a otra. Se desencadena una respuesta inmunitaria innata de tres vías: una vía dependiente de MyD88 que ocasiona citocinas inflamatorias, una vía STING/IRF3 que ocasiona una respuesta de interferón tipo I y una activación del inflamasoma de baja intensidad.

Los neutrófilos son decisivos para las defensas del hospedador durante las primeras 24 horas de la infección, en tanto que después es vital la afluencia de macrófagos activados procedentes de la médula ósea.

La inmunidad adquirida es indispensable para lograr la inmunidad estéril, la respuesta inmunitaria está mediada por células, los 
linfocitos T citotóxicos CD8+, que reconocen y destruyen a las células infectadas, los fagocitos activados circulantes destruyen las bacterias extracelulares resultantes de este proceso.

\section{MANIFESTACIONES CLÍNICAS}

La listeriosis humana generalmente se presenta como uno de los tres síndromes clínicos, a saber, gastroenteritis febril, listeriosis materno-fetal / neonatal o bacteriemia con o sin infecciones cerebrales, como meningitis, meningoencefalitis, rombencefalitis o absceso cerebral(9). Las infecciones focales menos comunes derivadas de la diseminación hematógena incluyen endocarditis, peritonitis, artritis séptica o endoftalmitis. También se han descrito infecciones focales que incluyen colecistitis, infección de prótesis articular e infecciones de injertos arteriales.

La mayoría de los casos de meningitis I menigoencefalitis listerial se observan en pacientes de 45 años y los síntomas predominantes son la alteración del sensorio y cefalea. Los signos meníngeos en la presentación son demostrables en 26 a $54 \%$, con menos frecuencia en los inmunodeprimidos. La tríada típica de meningitis bacteriana de fiebre, rigidez nucal y cambio en el estado mental se observa en el $43 \%$. Se pueden observar signos neurológicos focales del 16 al $37 \%$ y convulsiones en el 4 al $17 \% .(7)(9)$. El este caso el paciente nunca tuvo la triada típica de meningitis al igual que nunca presento focalización neurológica.

\section{DIAGNÓSTICO}

El diagnóstico requiere del aislamiento por cultivo de L. monocytogenes, por lo que siempre se deben tomar cultivos de sangre, y líquido cefalorraquideo (LCR)(10). En LCR, se presenta leve pleocitosis, la glucosa puede estar normal o baja, y solo una moderada cantidad de proteínas, y un tercio de los pacientes presentan resultados positivos de tinción de Gram, por estas características, que asemejan a una meningitis viral, el diagnóstico suele ser difícil, en casos en donde la tinción de Gram sea positiva, se debe diferenciar de Streptococcus pneumoniae y otras bacterias Gram positivas, y nos harán pensar en una listeria, al presentar características como catalasa positivas, que produzcan ácido de la D- glucosa, hidrolicen la esculina, den positivas las reacciones de VogesProskauer y del rojo metileno, y además sean móviles $(6,11,12)$.

En el caso de no estar seguros si se trata de una meningitis bacteriana versus viral, los niveles de ácido láctico proporcionan una prueba diagnóstica clave para la diferenciación temprana de la meningitis bacteriana aguda, donde se pueden presentar niveles de ácido láctico de $6 \mathrm{mmol} / \mathrm{L}$, mientras que en las meningitis virales $O$ asépticas los niveles son menores de $3 \mathrm{mmol} / \mathrm{L}$ (8). La PCR en tiempo real, representa la prueba más rápida disponible en la práctica clínica para la identificación de la bacteria y su tipificación (13).

\section{TRATAMIENTO}

Es de suma importancia reconocer los pacientes con factores de riesgo para meningitis por L. monocitogenes, ya que se ha visto que el tratamiento antibiótico inadecuado conlleva un aumento en la mortalidad con una significancia estadística (14).

La penicilina y la ampicilina constituyen el tratamiento inicial. Se considera que el antibiótico 
de elección de la bacteriemia o de la meningitis es la ampicilina en dosis meníngeas ( $2 \mathrm{~g}$ cada 4 h). La asociación de penicilinas con gentamicina actúa sinérgicamente frente a Listeria tanto in vitro como in vivo; Sin embargo, las ventajas del tratamiento combinado nunca han sido demostradas en estudios clínicos prospectivos.

En nuestro paciente se decidió en conjunto con infectología manejar solo con ampicilina debido a sus múltiples comorbilidades que le condicionaban un factor de riesgo de nefrotoxicidad. En un estudio retrospectivo, el tratamiento combinado no fue superior a la monoterapia con penicilina $(13,8)$.

Se sabe que los aminoglucósidos penetran poco en el líquido cefalorraquídeo sanguíneo y la barrera hematoencefálica, lo que genera preocupación sobre la eficacia de dicha terapia combinada de "primera línea" para las infecciones del sistema nervioso central debido a L. monocytogenes. Al menos en el huésped inmunocomprometido, la ampicilina en combinación con la rifampicina, que es efectiva contra la listeria intracelular y penetra en el LCR, podría ser un buen régimen alternativo para minimizar el riesgo de fracasos del tratamiento(15).

Los antibióticos como vancomicina, cuando se usan en pacientes con sospecha de meningitis, como tratamiento empírico y que posteriormente se aísla una Listeria, no han sido suficientemente efectivos para la resolución del cuadro, por lo que no se recomiendan para el uso cotidiano $(16,6)$.

En cuanto a la duración del tratamiento, en el caso de bacteriemias, dos semanas han demostrado ser suficientes para la resolución de la enfermedad, sin embargo se recomienda un uso más prolongado, de hasta 28 días de tratamiento (12).

El paciente recibió tres semanas de tratamiento presentando una resolución completa de sus síntomas y normalización de los reactantes de fase aguda

\section{BIBLIOGRAFÍA}

1. Jaime-Pérez JC, Elva P, Aguilar-Calderón, Salazar-Cavazos L, Gómez-Almaguer D. Evans syndrome: Clinical perspectives, biological insights and treatment modalities. J Blood Med. 2018;9:171-84.

2. Norton A, Roberts I. Management of Evans syndrome. Br J Haematol. 2006;132(2):125-37.

3. López Montes A, Andrés Mompeán E, Martínez Villaescusa M, Hernández Belmonte A, Mateos Rodríguez F, Abad Ortiz L, et al. Meningoencefalitis por Listeria en el lupus. An Med Interna. 2005;22(8):379-82.

4. Suárez MM, Bautista RM, Almela M, Soriano Á, Marco F, Bosch J, et al. Bacteriemia por Listeria monocytogenes: Análisis de 110 casos. Med Clin (Barc) [Internet]. 2007;129(6):218-21. Available from: http://dx.doi.org/10.1157/13107920 
5. Lomonaco S, Nucera D, Filipello V. The evolution and epidemiology of Listeria monocytogenes in Europe and the United States. Infect Genet Evol [Internet]. 2015;35:172-83. Available from: http://dx.doi.org/10.1016/j.meegid.2015.08.008

6. Pagliano P, Ascione T, Boccia G, De Caro F, Esposito S. Listeria monocytogenes meningitis in the elderly: Epidemiological, clinical and therapeutic findings. Infez Med. 2016;24(2):105-11.

7. Pagliano P, Arslan F, Ascione T. Epidemiology and treatment of the commonest form of listeriosis: Meningitis and bacteraemia. Infez Med. 2017;25(3):210-6.

8. Horta-baas G, Guerrero-soto O. Infección del sistema nervioso central por Listeria monocytogenes en pacientes con lupus eritematoso sistémico : análisis de 26 casos, incluyendo el reporte de un caso nuevo. 2013;9(6):340-7.

9. Drevets DA, Bronze MS. Listeria monocytogenes: Epidemiology, human disease, and mechanisms of brain invasion. FEMS Immunol Med Microbiol. 2008;53(2):151-65.

10. Tunkel AR, Hartman BJ, Kaplan SL, Kaufman BA, Roos KL, Scheld WM, et al. Practice Guidelines for the Management of Bacterial Meningitis. Clin Infect Dis. 2004;39(9):1267-84.

11. Capita R. Listeria monocytogenes y listeriosis. Dialnet [Internet]. 2009;15. Available from: https:// dialnet.unirioja.es/servlet/articulo?codigo $=3429492$

12. Del Brutto $\mathrm{OH}$. Infecciones micóticas del sistema nervioso central. Rev Ecuatoriana Neurol. 2000;9(3):44-60.

13. Van de Beek D, Cabellos C, Dzupova O, Esposito S, Klein M, Kloek AT, et al. ESCMID guideline: Diagnosis and treatment of acute bacterial meningitis. Clin Microbiol Infect. 2016;22:S37-62.

14. Thønnings S, Knudsen JD, Schønheyder HC, Søgaard M, Arpi M, Gradel KO, et al. Antibiotic treatment and mortality in patients with Listeria monocytogenes meningitis or bacteraemia. Clin Microbiol Infect [Internet]. 2016;22(8):725-30. Available from: http://dx.doi.org/10.1016/j. cmi.2016.06.006

15. Reardon P, Reardon M. Listeria Monocytogenes Meningitis in an Immunocompetent Adult. Dalhousie Med J. 2013;40(1):113-8.

16. Lim S, Chung DR, Kim YS, Sohn KM, Kang SJ, Jung SI, et al. Predictive risk factors for Listeria monocytogenes meningitis compared to pneumococcal meningitis: a multicenter case-control study. Infection. 2017;45(1):67-74.

\section{(ब)}

